\title{
INTRODUCTION OF CONSTRUCTION MANAGEMENT INTEGRATED SYSTEM USING BIM IN THE HONAM HIGH-SPEED RAILWAY LOT NO. 4-2
}

\author{
Hyun Cho ${ }^{1}$, Ki Hwan Lee ${ }^{1}$, Song Hyon Lee ${ }^{1}, \underline{\text { Ta Lee }^{1}}$, Hyun Jun $\mathrm{Cho}^{1}$, Sung Hoon $\mathrm{Kim}^{2}$ and Sang Hyeok Nam ${ }^{2 *}$ \\ ${ }^{1}$ Civil Engineering Technology Department, Ssangyong E\&C, Seoul, Korea \\ ${ }^{2}$ Research Institute, IDM E\&C, Seoul, Korea \\ * Corresponding author (hjcho@ssyenc.com)
}

\begin{abstract}
The Honam High-Speed Railway Lot No.4-2 consisting of 6 bridges including the arch bridge, the extradosed bridge and 2 tunnels with a total length of $9.38 \mathrm{~km}$ and the whole construction work should be completed within 31 months only. In order to control the detailed cost and the construction process thoroughly, the construction management integrated system based on BIM(Building Information Modeling) has been developed and adopted firstly by the Civil Engineering Technology Dept. of Ssangyong E\&C in Korea. In this paper, the application of the construction management integrated system using BIM on the Honam High-Speed Railway Lot No. 4-2 has been introduced. This system is mainly made up of the full-range 3D information models and the web-based 5D system models. The web-based 5D system is composed of the safety and equipment management modules using virtual reality as well as the 4D earthwork quantity control system. Through the construction management integrated system based on BIM, an integrated on-site management can be achieved, especially in the best cost adjustment, construction management and safety conditions.
\end{abstract}

Keywords: High-Speed Railway, BIM, Construction Management Integrated System, Web-Based 5D System, Safety and Equipment Management

\section{INTRODUCTION}

Recently, IT technology has become a key component of technical development to improve productivity in construction fields. The information modeling technology is considered as an innovation of civil engineering using the technology fusion in construction. BIM (Building Information Modeling) has become a proven technology in other industry fields including architecture, mechanics, and so on. BIM is a revolutionary technology and process that has transformed the way infrastructures are designed, analyzed, constructed, and managed. 3D construction schedule management called 4D simulation has an advantage that visual simulation is available with $3 \mathrm{D}$ models linked to the process data. [1, 2]

In this paper, the construction management integrated system using BIM technique is introduced which is applied to the Honam high-speed railway lot no. 4-2 consisting of 6 bridges and 2 tunnels with a total length of $9.38 \mathrm{~km}$. This system is made up of full-range $3 \mathrm{D}$ information models including all surrounding geographical features. The 3D earthwork plan, safety management, and equipment operation system were built in the web-based 5D integrated system which added quantity and cost to 4D system. Fig. 1 shows the composition of construction management integrated system using BIM.

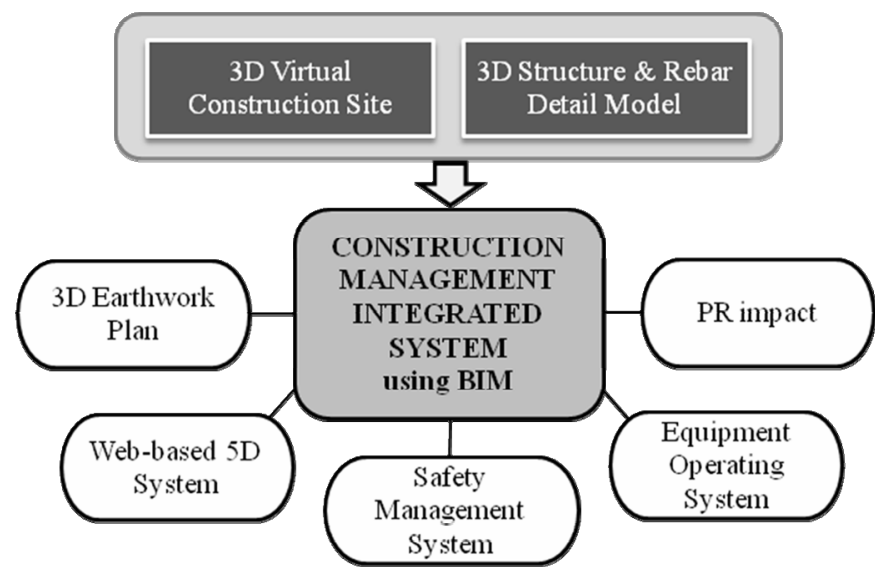

Fig. 1 Composition of construction management integrated system using BIM 


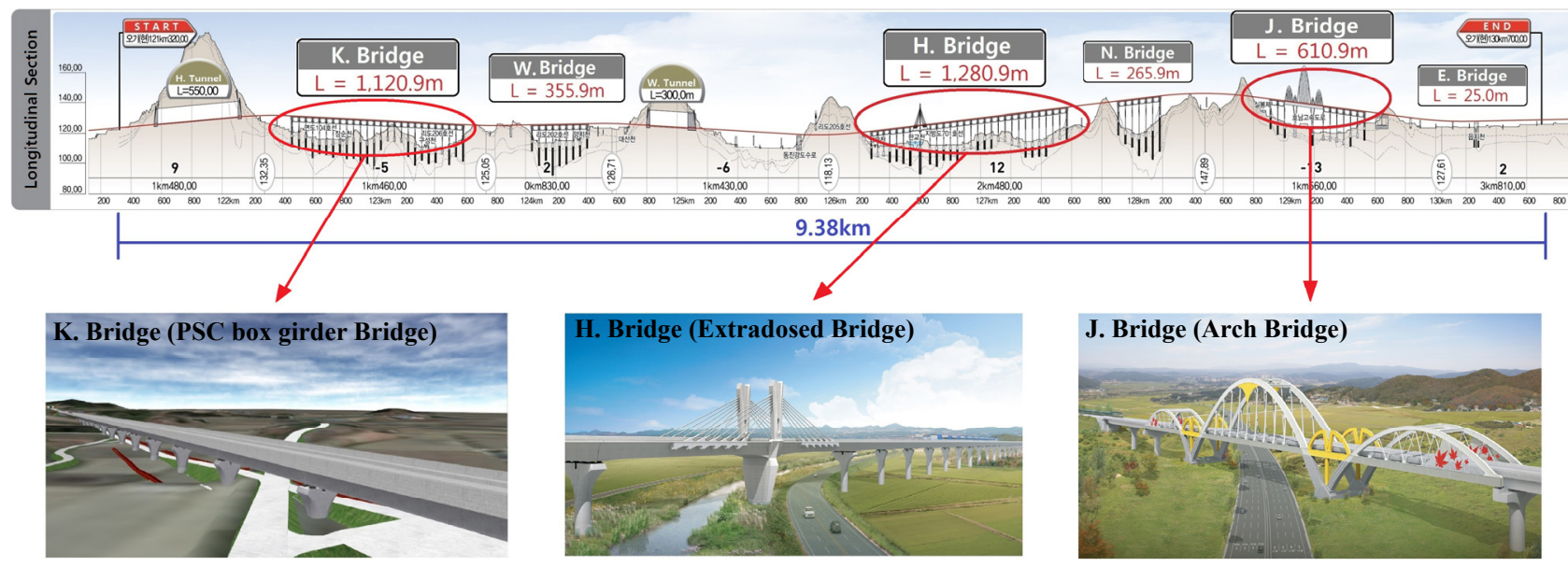

Fig. 2 Honam high-speed railway lot no. 4-2

The major effects of the integrated on-site management using this system are as follows.

First of all, the validity of design can be checked in advance by establishing 3D models of the whole construction site. The 5D system is the best way to reduce the period and the cost of construction. The construction safety can be guaranteed through the combination of safety management and equipment operation in virtual construction site. [3, 4] Also, this 3 dimensional system can be used for public relations purpose.

Finally, through the 3D Construction Management Integrated System using BIM technology, the best construction management with safety can be achieved.

Fig. 2 shows the longitudinal section of Honam high-speed railway lot no. 4-2 and the modeling of major bridges.

\section{APPLICATION OF 3D INFORMATION MODEL}

The 3D information modeling has been applied for the whole project of Honam high-speed railway lot no. 4-2.

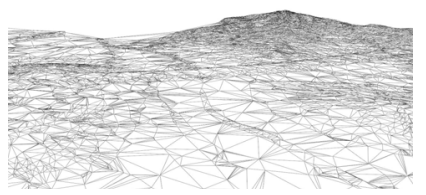

(a) 3D Lay of the land

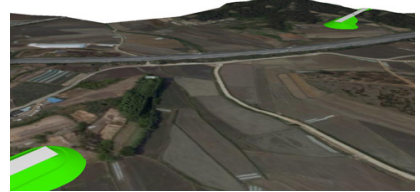

(c) 3D Earthwork model

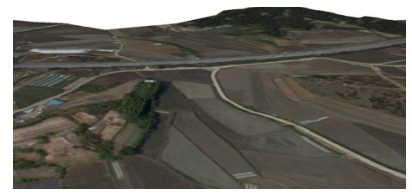

(b) Virtual site

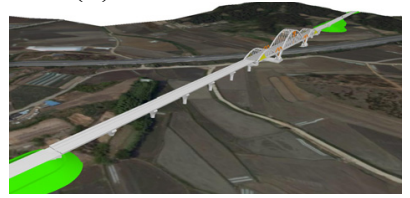

(d) 3D Structure model

Fig. 3 Establishment of virtual construction site

First of all, in order to establish the 3D virtual construction site, surveying data and aerial photographs were used for mapping, based on which the modeling was made as shown in Fig. 3.

\subsection{D Structural Model}

Since the 3D structural models were based on accurate sectional dimensions and positional information, it can be very helpful for the on-site construction (Fig. 4).

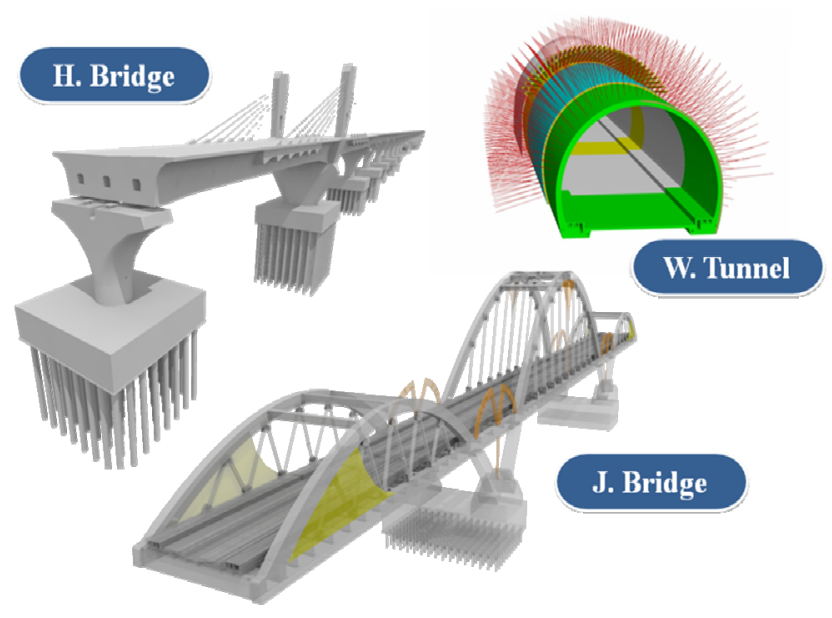

Fig. 4 3D Structural modeling

Also, mistakes or errors of the design can be checked and modified with these 3D structural models. Fig. 5 and Fig. 6 show the examples of accuracy check for the pier coping. As shown in these figures, several design errors were found in the original design for the complicated shaped structural part. These errors could be modified by using 3D 
structural models. In the Honam high-speed railway project lot no. 4-2, about 70 errors were found in the original design.

In addition, various 3D simulations can be created in the virtual reality using the $3 \mathrm{D}$ information models. This simulation system can be operated wherever your internet connection is possible, because the system is web-based.

The 3D information model including the lay of the land can be used for basic model of the 4D or 5D management system as well as the design validity check. Since these 3D models have exact coordinates, dimensions, and properties, it can also be used to calculate the quantity accurately for various construction projects.
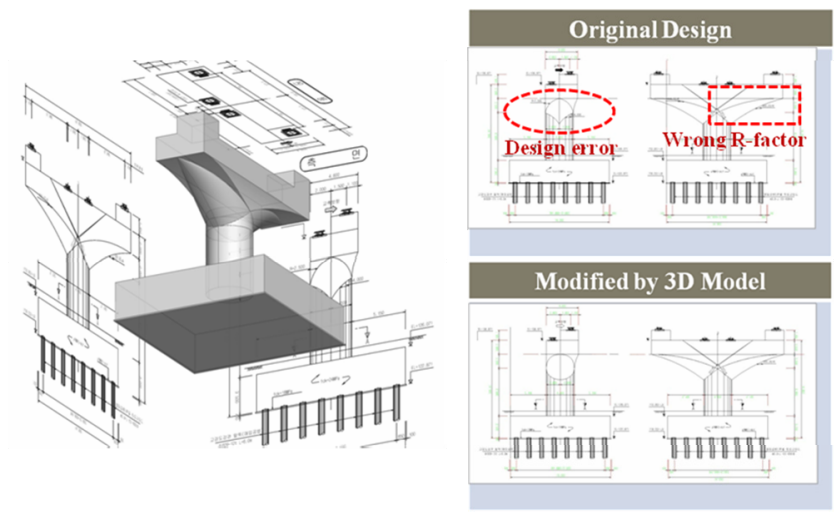

Fig. 5 Accuracy check for the shape of structures

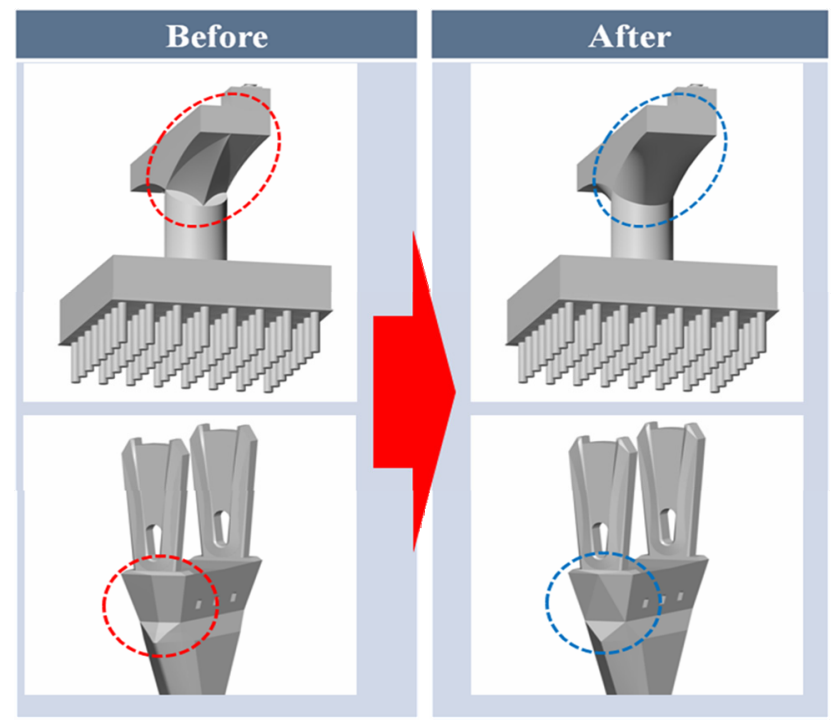

Fig. 6 Modified shape of structures

\subsection{Digital Mock-up}

The 3D reinforcement modeling has been applied in part for constructability check of the reinforced concrete structures under the name of DMU (digital mock-up). In this paper, the $3 \mathrm{D}$ reinforcement models were built for the reinforced concrete structures of the whole project section to check the quantity and constructability of reinforcing bars as well as the accuracy of reinforcement details.

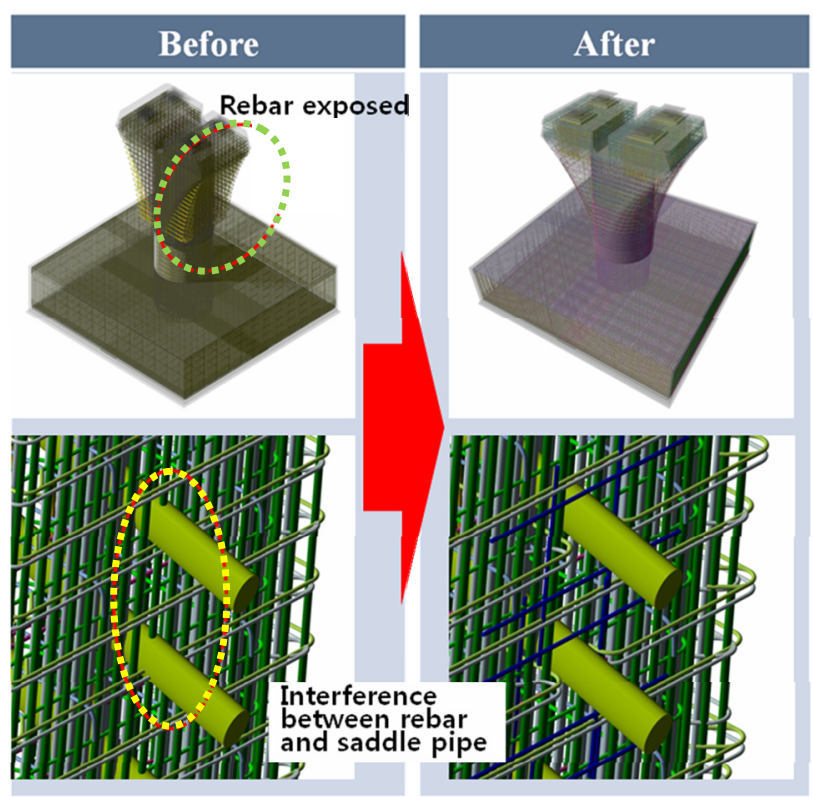

Fig. 7 Modified reinforcing bar detail

Fig. 7 shows the cases of design errors that the reinforcing bar is exposed out of the concrete surface and interference occurred between the reinforcing bar and the saddle pipe.

Fig. 8 and Fig. 9 show the rebar details for the pylon part and the foundation part of bridges. The amount of reinforcing bar calculated by $3 \mathrm{D}$ rebar details were compared with the original design result as shown in Table 1 and Table 2. As shown in these tables, the total amount of reinforcing bar could be increased or decreased as the case may be. It is mostly due to the simple mistakes of designers when they drew the reinforcing bar details or made the material tables. In the majority of cases, the total amount of rebar can be reduced by using the 3D rebar detail model except the designer's mistakes. As a result, reinforcing bar saving as well as constructability checking 
can be achieved through the digital mock-up using 3D rebar models.

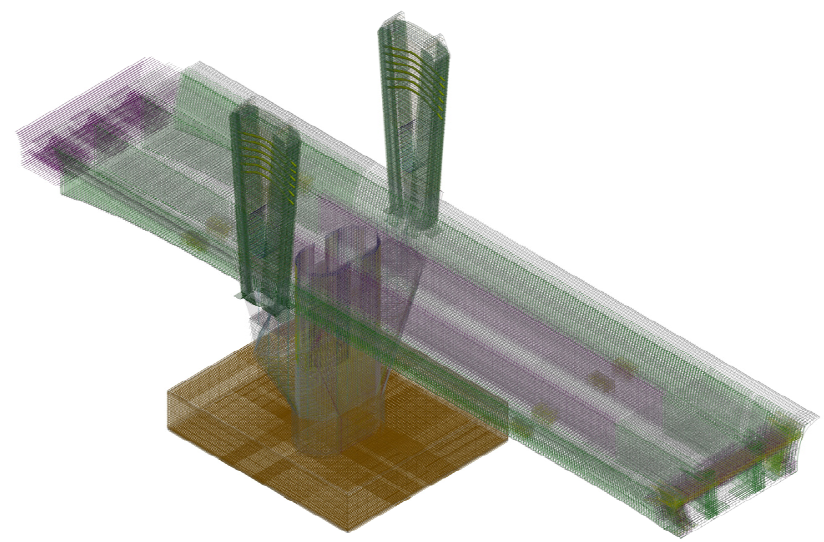

Fig. 8 Rebar details of pylon part

Table 1 Amount of reinforcing bar for pylon

\begin{tabular}{|c|c|c|c|c|c|c|}
\hline Item & H32 & H29 & H19 & H16 & H13 & Total $(\mathrm{t})$ \\
\hline 2D Design & 85.45 & 131.11 & 5.10 & 30.74 & 0.12 & 252.52 \\
\hline 3D Model & 70.53 & 133.01 & 5.00 & 30.80 & 0.12 & 239.45 \\
\hline
\end{tabular}

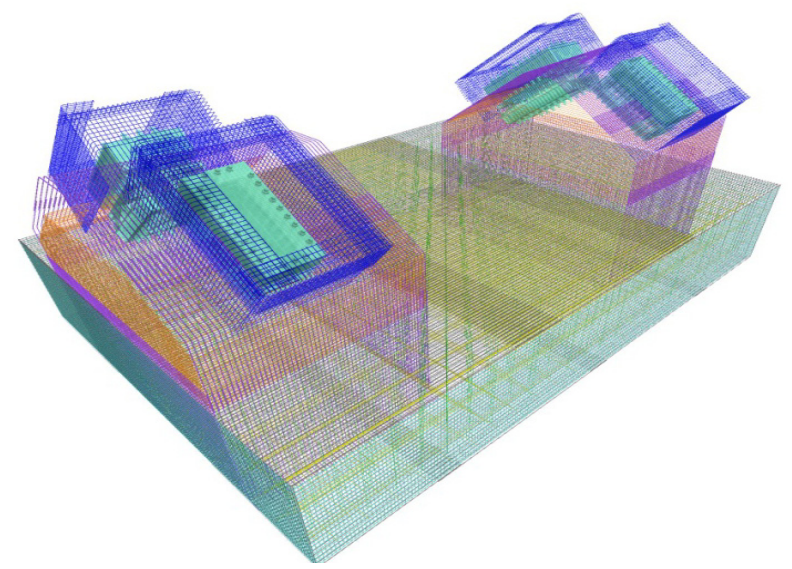

Fig. 9 Rebar details of foundation part

Table 2 Amount of reinforcing bar of foundation

\begin{tabular}{|c|c|c|c|c|c|c|}
\hline Item & H32 & H29 & H25 & H19 & H13 & Total $(t)$ \\
\hline 2D Design & 16.82 & 11.55 & 76.12 & 26.71 & 3.69 & 134.89 \\
\hline 3D Model & 16.82 & 11.41 & 88.18 & 25.22 & 3.74 & 145.37 \\
\hline
\end{tabular}

\section{CONSTRUCTION MANAGEMENT}

\section{INTEGRATED SYSTEM USING BIM}

The construction management integrated system using BIM techniques has been operated on the web site for the collaboration of the construction project's participants. Close collaboration is the main condition ensuring the effective management of a construction project, which can be fulfilled by using $4 \mathrm{D} / 5 \mathrm{D}$ modeling concept. $[5,6]$ This system is constructed on the web site as shown in Fig. 10. (http://www.ssybim.com)

\subsection{Web based 4D/5D system}

The 3D information model (or so-called BIM) may be the best way for the project planning and designing. It can also be efficiently used in the construction management.

The 4D/5D system, which is the major factor of the construction management integrated system using BIM, is linked with the managing program for schedule and cost used in the real construction site. The 3D model is linked with the schedule and cost data after the classification according to the work types. Fig. 11 shows the 5D system of Honam high-speed railway lot. no. 4-2 constructed on the website. In this web based system, 3D construction simulation is available according to the construction procedure.

As shown in this figure, using the 5D system, it is possible not only to get the original location and position in the $3 \mathrm{D}$ virtual site, but also to check the 3D simulation of the project process on a certain day. Also, by simply clicking of the Gantt chart and the working breakdown system below, it can be easily to get the information of quantities and cost.

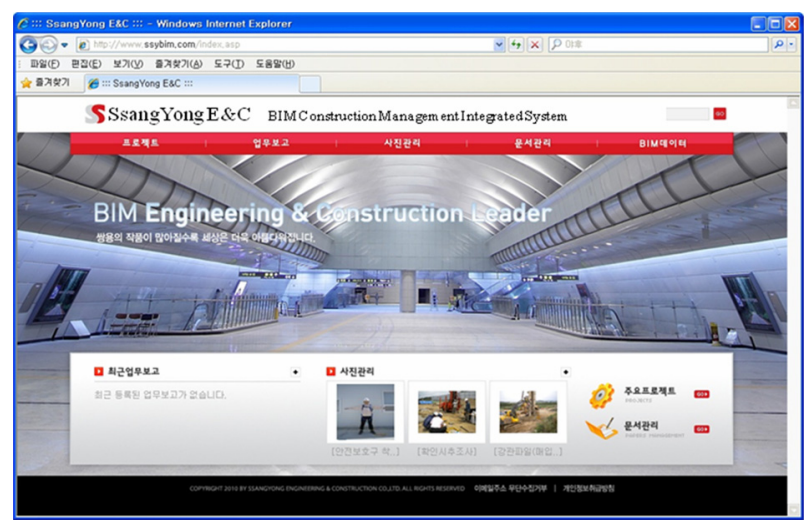

Fig. 10 Website of Construction Management System 


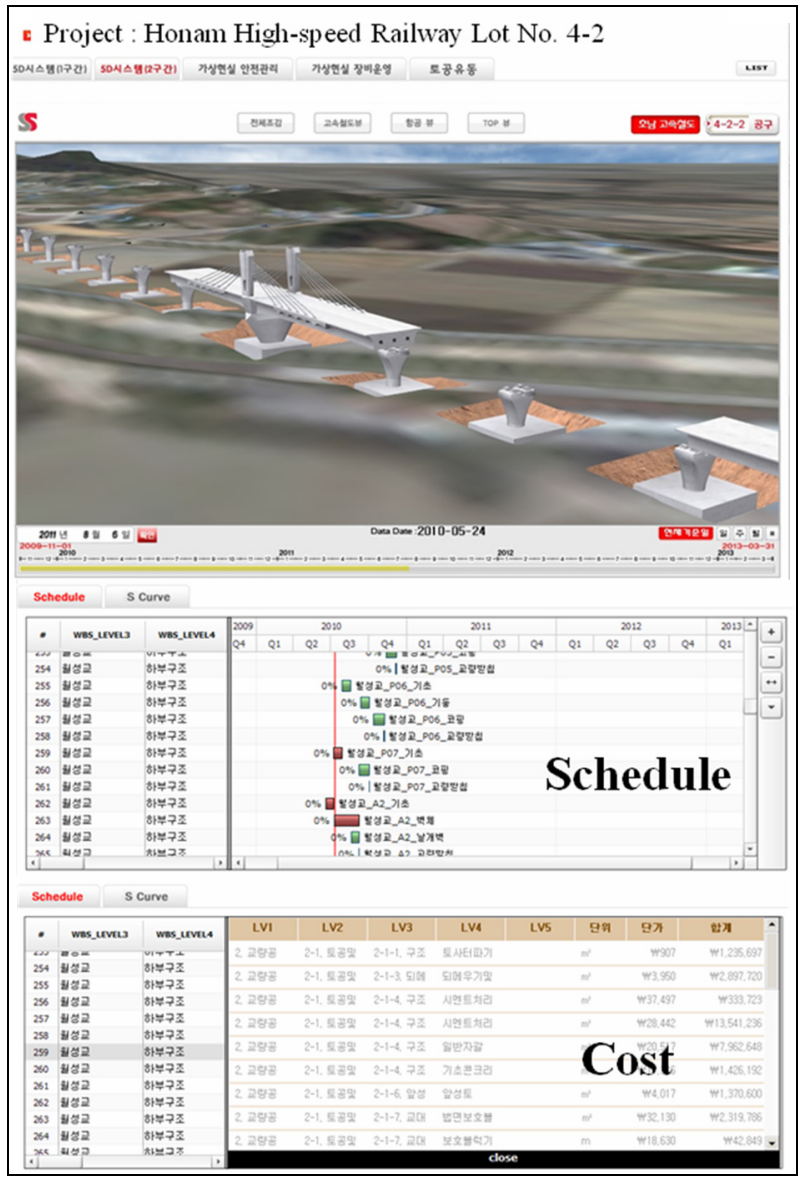

Fig. 11 Web-based 4D/5D system

\subsection{Safety management with Avatar}

The safety management system with construction Avatar was developed which allows you to move freely and access everywhere inside the 3D virtual construction site. The Avatar was created to have the same features with the onsite construction worker who wears the safety equipments as shown in Fig. 12. This Avatar can move like human beings in the $3 \mathrm{D}$ virtual construction site by keyboard control of the user. Besides the simple on-site checking, this system also provides specific risk assessment data for different positions on the construction site, based on the standards of the Korea Occupational Safety and Health Agency, KOSHA 18001 as shown in Fig. 13. This system is made up to identify the safety management items when the Avatar approaches the corresponding position. Thus, this system can be utilized as a training material to instruct the safety management items visually for the construction workers by the Avatar's moving in the virtual construction site.
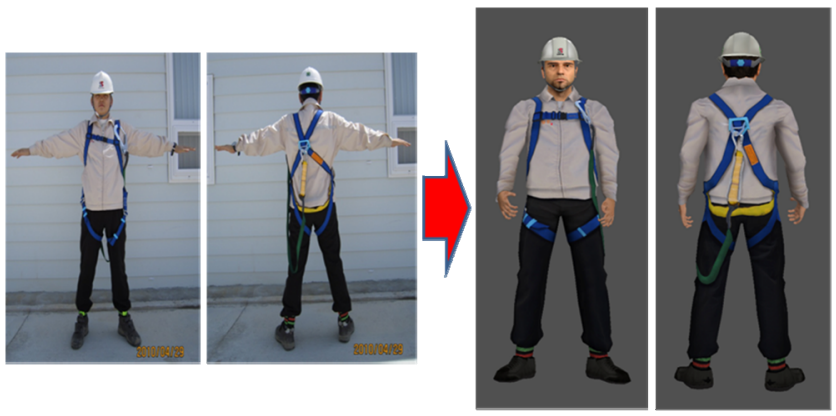

Fig. 12 Creation of the Avatar

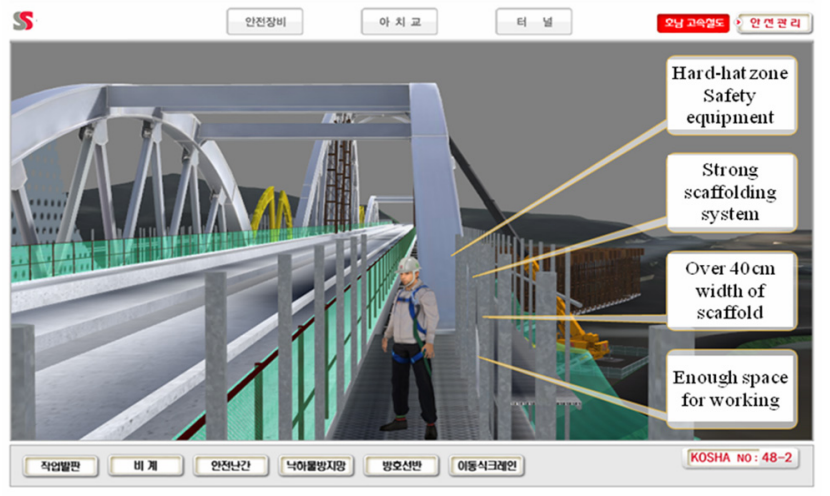

Fig. 13 Safety management system with Avatar

\subsection{Equipment operation in the virtual construction site}

It is possible to operate the equipment model as well as the avatar model in this virtual construction site. This equipment model can be operated by the computer keyboard for moving and even controlling the angle and length of boom. The operator can check the capacity of the equipment easily in real time. Fig. 14 shows the equipment operating simulation using 3D model for 330ton and 440ton capacity cranes. The 330ton capacity crane was satisfied for hoisting 29.8 ton with $46.9 \mathrm{~m}$ of boom length at the planning stage. But the crane should be changed to 440ton capacity crane due to the setting position and the boom angle of the crane considering the construction site conditions. Table 3 shows the comparison of crane capacity by the boom angle and length.

Besides the interfering matters like the movement of the equipment, the types, sizes and construction safety of the equipments can also be managed. Thus, the safe and fast construction may be available through the $3 \mathrm{D}$ simulation system for optimized equipments and its various combinations. 


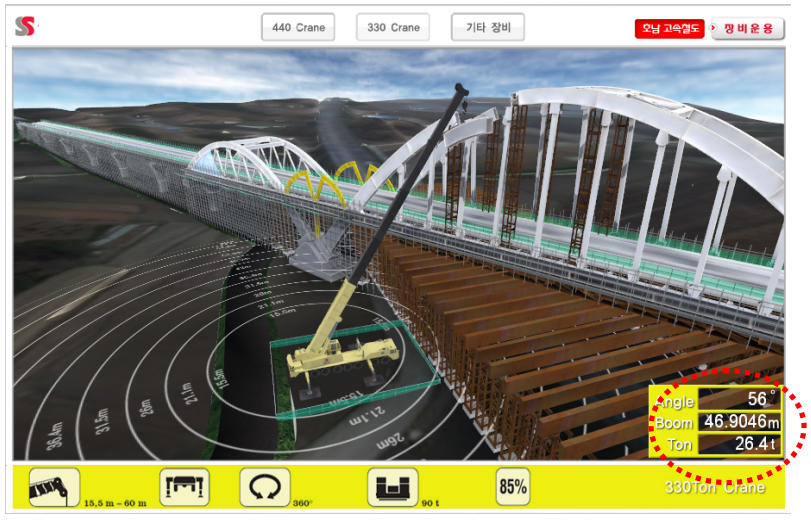

(a) 330ton capacity crane

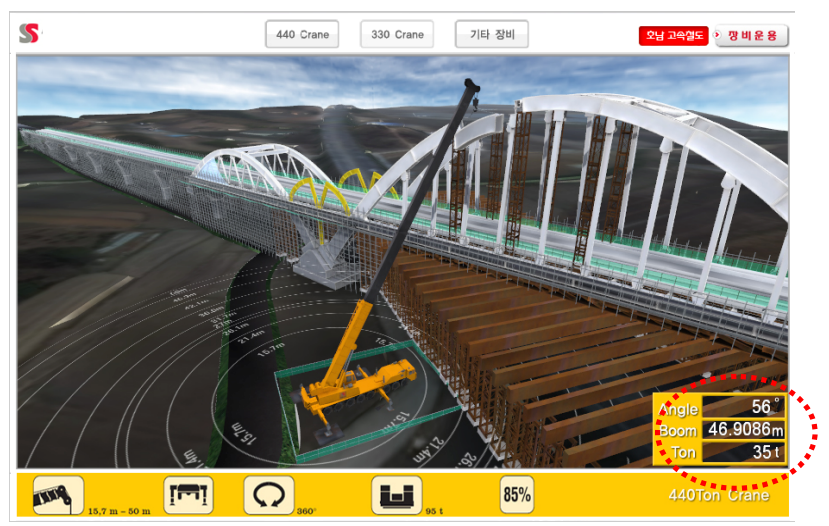

(b) 440ton capacity crane

Fig. 14 The operating simulation for cranes

Table 3 Comparison of hoisting capacity

\begin{tabular}{|c|c|c|c|}
\hline Item & Boom angle & Boom length & Capacity \\
\hline 330ton & $56^{\circ}$ & $46.9 \mathrm{~m}$ & 26.4 ton \\
\hline 440ton & $56^{\circ}$ & $46.9 \mathrm{~m}$ & 35.0 ton \\
\hline
\end{tabular}

\section{CONCLUSION}

The construction management integrated system using BIM techniques has been applied to the construction project of Honam high-speed railway Lot No. 4-2. Table 4 shows effects of the construction management integrated system for the construction projects. As shown in this table, the BIM technology applied into construction project could be used in various fields with great efficiency.

In a long-term view, the BIM technology would be the technology fusion in construction which can make higher productivity through the reducing of materials, times, and costs of the construction.
Table 4 Effects of construction management integrated

\begin{tabular}{|c|c|}
\hline $\begin{array}{c}\text { 3D structural } \\
\text { Modeling }\end{array}$ & $\begin{array}{c}\text { Advance solution for construction } \\
\text { delaying factor by preliminary check of } \\
\text { design results }\end{array}$ \\
\hline $\begin{array}{c}\text { 3D earthwork } \\
\text { plan }\end{array}$ & $\begin{array}{c}\text { Optimized earthwork plan and } \\
\text { excavation schedule }\end{array}$ \\
\hline $\begin{array}{c}\text { 3D Rebar } \\
\text { detail model }\end{array}$ & $\begin{array}{c}\text { Constructability check for details } \\
\text { Optimized rebar quantity }\end{array}$ \\
\hline $\begin{array}{c}\text { 5D } \\
\text { management } \\
\text { system }\end{array}$ & $\begin{array}{c}\text { Management for optimized construction } \\
\text { periods, equipments, and materials }\end{array}$ \\
\hline $\begin{array}{c}\text { Safety } \\
\text { management }\end{array}$ & $\begin{array}{c}\text { Improve the safety through the safety } \\
\text { management and education }\end{array}$ \\
\hline $\begin{array}{c}\text { Equipment } \\
\text { operating } \\
\text { system }\end{array}$ & $\begin{array}{c}\text { Preliminary construction plan by } \\
\text { equipment operating simulation }\end{array}$ \\
\hline
\end{tabular}

\section{REFERENCES}

[1] Eastman C., Teicholz P., Sacks R. and Liston L., BIM Handbook - A Guide to Building Information Modeling for Owners, Managers, Designers, Engineers, and Contractors, John Wiley \& Sons, Inc., 2008.

[2] Kymmell W., Building Information Modeling Planning and Managing Construction Projects with 4D CAD and Simulations, McGraw Hill, 2008.

[3] Smith D. K. and Taradif M., Building Information Modeling - A Strategic Implementation Guide for Architects, Engineers, Constructors, and Real Estate Asset Managers, John Wiley \& Sons, Inc., 2009.

[4] Hardin B., BIM and Construction Management Proven Tools, Methods, and Workflows, Wiley Publishing, Inc., 2009.

[5] Popov V., Juocevicius V., Migilinskas D., Ustinovichius L. and Mikalauskas S., "The use of virtual building design and construction model for developing an effective project concept[ in 5D environment", Automation in Construction, Vol. 19(3), pp. 357-367, 2010.

[6] Hu Z. and Zhang J., "BIM- and 4D-based integrated solution of analysis and management for conflicts and structural safety problems during construction: 2 . Development and site trials", Automation in Construction, Vol. 20(2), pp. 167-180, 2011 